\title{
Part-Solid Ground-Glass Pulmonary
} Nodule

National Cancer Institute

\section{Source}

National Cancer Institute. Part-Solid Ground-Glass Pulmonary Nodule. NCI Thesaurus.

Code C113719.

A term that refers to a pulmonary nodule in which part of the ground-glass opacity completely obscures the parenchyma on CT scan examination. 